\title{
Gi-Fi: A Revolution in Wireless Communications
}

\author{
Maha Elnour Mekki Awoda ${ }^{1}$, Aisha-Hassan A. Hashim², \\ Mohammad Kamrul Hasan ${ }^{2}$ \\ ${ }^{1}$ Faculty of engineering, AL - Neelain University, Khartoum, Sudan \\ ${ }^{2}$ Department of Electrical and Electronics Engineering, \\ University Malaysia Sarawak (UNIMAS), Malaysia \\ maha19722@hotmail.com
}

\begin{abstract}
GiFi or gigabit wireless technology embodies the dream of home wireless next quickly and they do not need to combinations complex nor expensive nor TRXs. GI-FI is the world's first transceiver integrated on a single chip that operates at $60 \mathrm{GHz}$ on the CMOS process. They used technique dual division of time that separates the incoming signals from emerging. They SIM abbreviated shortly so the arrival of the video time and is working to balance speed with each other. The development will enable the truly wireless office and home of the future. As the integrated transceiver is extremely small, it can be embedded into devices. GI-FI technology provide many features such as small form factor, high speed data transfer, low power consumption. In this paper, a concrete assessment will be done on Gi-fi and compared them with Bluetooth and Wi-Fi, WiMAX and clarified the most significant GI-Fi features to be the dream of current technology.
\end{abstract}

Keywords: Gi-Fi, Wi-Fi, WiMAX.

\section{Introduction}

The reality of the rapid life requests to get the technology to eliminate our needs in the fastest and high quality with few possibilities of time was therefore hoc basis for the development of cable wired to the Wireless. A wireless LAN (or WLAN) for wireless local area network, or can named as (LAWN) means local area wireless network. This techniques change the world telecommunication by using wireless LAN instead of network cabling in [11]. It became the evolution of Bluetooth and Wi-Fi are the backbone of modern technology, but we are still in the non-satisfaction of each of our desires and the collision with reality accelerated and then came Wimax faster 100 times and the scope wider, but did not find its way in our daily lives after 10 years on Wimax. The hoc basis and research into new techniques have been LI-FI came up to us and at higher speeds, and a team of researchers at the University of Melbourne came the invention of the Australian GI-FI was his leadership and his ability to predict the face of racing against time. The aim of this study is to is discuss the work of GI-FI using papers that published it and access to the latest information required for the advancement of this technology and to satisfy the desires of our lives. This paper investigates the GI-FI that impact on wireless LAN by using survey in published papers focusing on gi fi benefits. The paper is designed as follows: Section 2 provides related 
works. In section 3, what is the GI-Fi? In section 4, Why GI-Fi? Finally, the conclusion of the paper is given.

\section{Related Works}

There are a number of papers published about Gi-Fi cross-sectional its benefits and its importance to the world in general and the development and considered a revolution in the world only wireless communications. In [1] the comparisons underwent previous techniques and found some fringe benefits suggested GI-Fi on other technologies such as high speed and the short-term use in the. media, but the LI- FI can work infrastructure for its high price tag. In [2], WiFi compared techniques Wireless found that most use Although WiMAX faster than data transfer 100 times, while the GI-Fi, which is the fastest $(5 \mathrm{~GB})$ of LI- FI (more than $3 \mathrm{~GB}$ ), but he did not find his way in the ground, despite the advantages that underlie this technique. In [3], the comparing GI-Fi mobile Web technologies and current Compare Rooms found that GI-Fi characterized by frequency interference and low cost technical and energy. In [4], author concluded that GI-Fi solution to the problem of high data transmission and high energy consumption and all that device to send and receive integrated. In [5], author illustrated for the first time there is a technique in GI-Fi integrated send the receiver in one chip at $60 \mathrm{GHz}$ on cmos. The paper also assumed that the role of modern technology in the digital economy future. In [6 ], The author noted, how the evolution of GI-Fi network by linking computer servers and mobile and the laptops connected to the computers (see Fig. 1) and to the flexibility of movement and speed of data transfer and low energy consumption which increases in the evolution of technology.

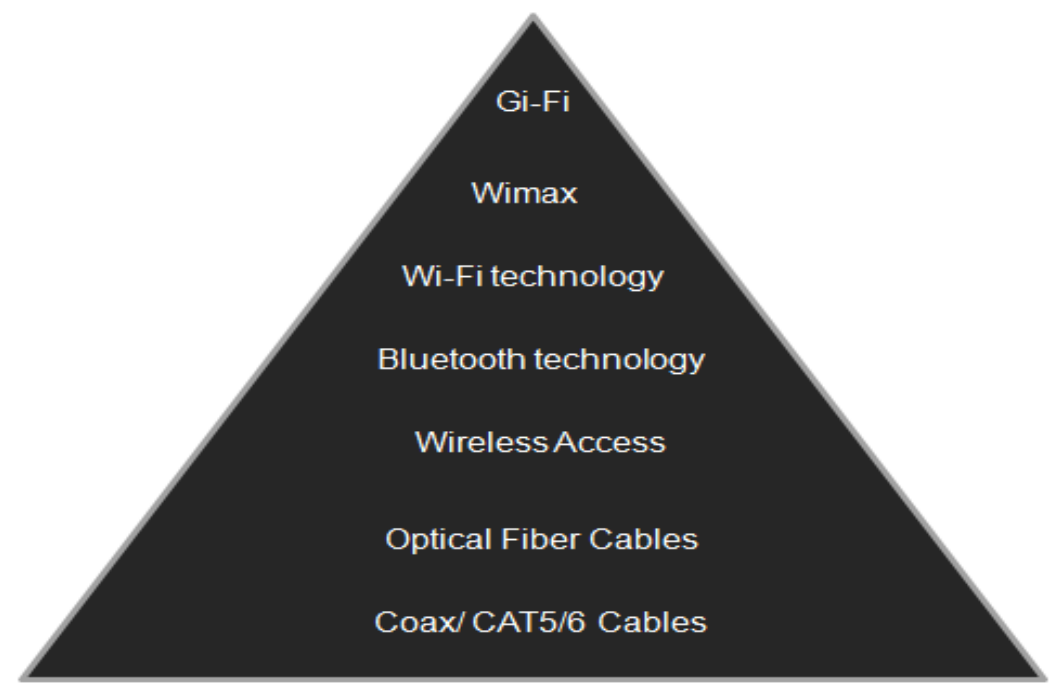

Fig.1. Gi-Fi technology evolution

In [7] the study concentrated on GI Fi technology and despite its small size transceiver. It works in the $60 \mathrm{GHz}$ technology up a 5-Gbps, making it the best and the latest in technology in addition to the features which promise lower energy 
and do not use cables as well as the security services Higher \& simplicity. In [8] authors have discussed the $\mathrm{Gi}$ Fi appropriate technical data to replace current wireless technologies. In [9], the study focused on comparisons between $\mathrm{Gi}-\mathrm{Fi}$ and Wi-Fi and Bluetooth concluded, including appropriate technical GI-Fi to be the best solution in order to speed by high security and simplicity and low capacity and small size etc. In [10], the comparing of GI-Fi wireless technologies and current Compare Rooms found that GI-Fi characterized by frequency interference and low cost technical and energy consumption. The advantages and drawbacks for the current proposals are summed up in Table 1.

\section{What is the GI-Fi?}

Wi-Fi (IEEE 802.11b) and WiMAX (IEEE-802.16e) have captured our attention. As there is no recent developments which transfer data at faster rate, as video information transfer taking lot of time. This leads to introduction of Gi-Fi technology. It offers some advantages over Wi-Fi, a similar wireless technology. In that it offers faster information rate in Gbps, less power consumption and low cost for short range transmissions [12]. Gi-Fi which is developed on a integrated wireless transceiver chip. In which a small antenna used and both transmitter- receiver integrated on a single chip which is fabricated using the complementary metal oxide semiconductor (CMOS) process. Because of Gi-Fi transfer of large videos, files will be within seconds. Researchers in the field of telecommunications in Australia at the University of Melbourne, led by the world's Australian Stan and 27 researcher doing Gi-Fi system wireless speeds of up to 5 Jajavy the second in scale range is 10 times the transfer rate wireless now used by integrated module transmitter and wireless receiver a frequency $(60 \mathrm{GHz})$ in a small-sized chip. $(5 \mathrm{~mm})$ and use an antenna $(1 \mathrm{~mm})$ and power consumption are very few milliwatts's highlights. Two units GI-Fi is a terminal with Jordan Home subscribers (Iee IEEE-802.16c) standard.

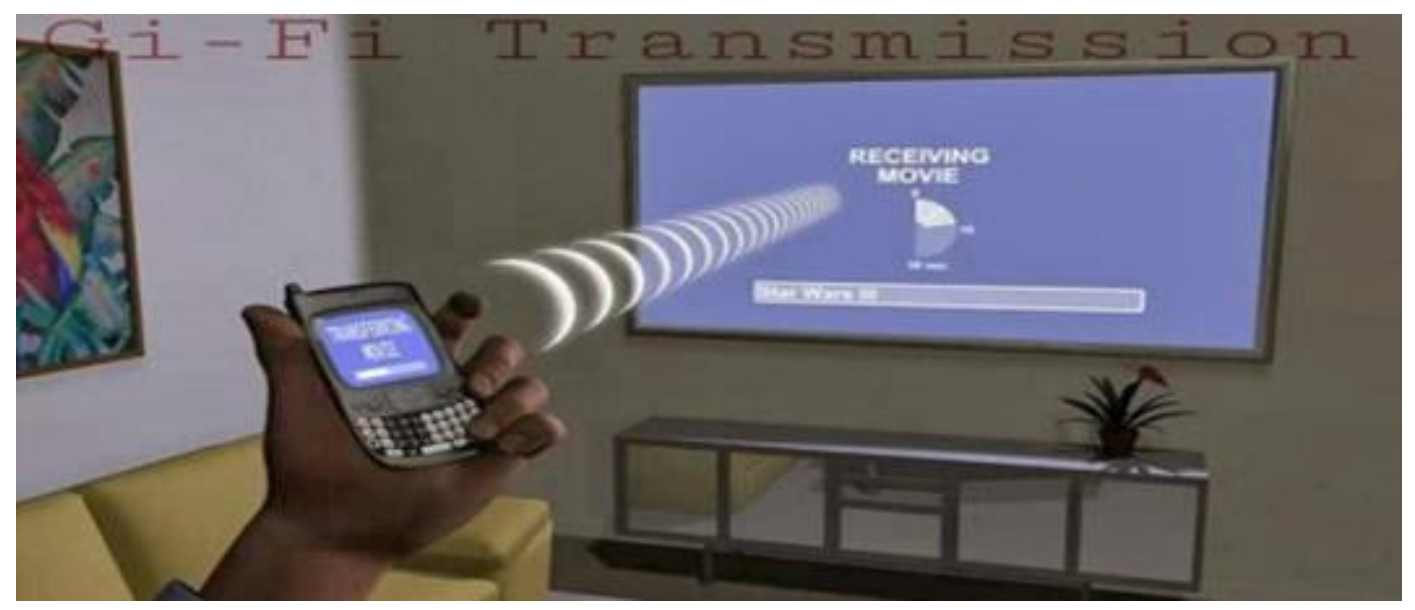

Fig.2. Reference application of Gi-Fi [12]

Gi-Fi or gigabit wireless is that the world's initial transceiver integrated on one chip that operates at $60 \mathrm{GHz}$ on the cmos method. It'will enable wireless transfer of audio and video knowledge at up to 5gigabits per second, 10 times this most wireless transfer 
rate, at common fraction the value. NICTA researchers have chosen to develop this technology within the $57-64 \mathrm{GHz}$ unauthorized waveband because the millimeterwave vary of the spectrum makes potential high part on-chip integration further as leaving the mixing of terribly little high gain arrays. The accessible $7 \mathrm{GHz}$ of spectrum ends up in terribly high knowledge rates, up to five gigabits per second to users inside an internal setting, sometimes inside a spread of ten meters .It satisfies the standards of IEEE 802.15.3C .The Gi-Fi integrated wireless transceiver chip. Using a number of access points [5]. This is technically able to link wireless networks in offices or homes to both have evolved to the point amazing her magazine capacity for International Research \& T has predicted in its issue of January \February 2013 will be in the few coming years will be the new future for the world of telecommunications [10]. Wi-Fi (IEEE-802.11b) and Wi-Max (IEEE-802.16e) have captured our attention [14-15], as there are no recent developments in the above technologies which cannot transfer data and video information at a faster rate and led to the introduction of Gi-Fi technology. It offers some advantages over Wi-Fi, a similar wireless technology, that offers faster information rate in Gbps less power consumption and low cost for short range transmissions. Gi-Fi or Gigabit Wireless is that the world's initial transceiver integrated on one kick in that a little antenna used and each transmitter-receiver ar integrated on one chip that is fictional victimization the complementary metal chemical compound semiconductor method. Owing to Gi-Fi transfer of enormous videos, files is done inside seconds. Researchers of Melbourne University has return up with a wireless technology that guarantees high speed short vary knowledge transfers with a speed of up to $5 \mathrm{Gbps}$ inside a radius of ten meters. The new wireless technology is called as Gi-Fi and operates on the $60 \mathrm{GHz}$ waveband, which is presently largely unused. The Gi-Fi Chip developed by the Australian researcher's measures $5 \mathrm{~mm}$ sq. and is factory-made victimizations existing complementary metal-oxide-semiconductor (CMOS) technology, constant system that's presently accustomed print semiconductor chips. The best half regarding this new technology is its value effectiveness and power consumption, it consumes solely 2 watts of power for its operation with antenna $(1 \mathrm{~mm})$ enclosed and also the development of Gi-Fi chip prices or so $\$ 10(\mathrm{Rs} 380)$ to manufacture. In theory this technology would transfers GB's of your favorite high definition movies in seconds. Therefore Gi-Fi is thought of as a rival to Bluetooth instead of Wi-Fi and will realize applications starting from new mobile phones to shopper physical science.

\subsection{REASONS FOR OPTING GI-FI:}

The explanation for pushing into Gi-Fi technology is owing to slow rate, high power consumption, low vary of frequency operations of earlier technologies Bluetooth

\section{Significance of GI-Fi?}

From the table above note distinguish GI-Fi compared to his counterparts of the techniques it provides all the required needs in addition to excellence in several aspects: First: speed, is high: We find that the speed of the video and audio transfer is very fastest 5 Gbps Comparative Wi-Fi and li-Fi and Bluetooth. This technique has been 
developed using a single chip can be integrated with any electronic device or the Home Office used to transfer video quickly high time of 5 Gbps) [1]. In Fig.1, the Gi-Fi access devices are shown.

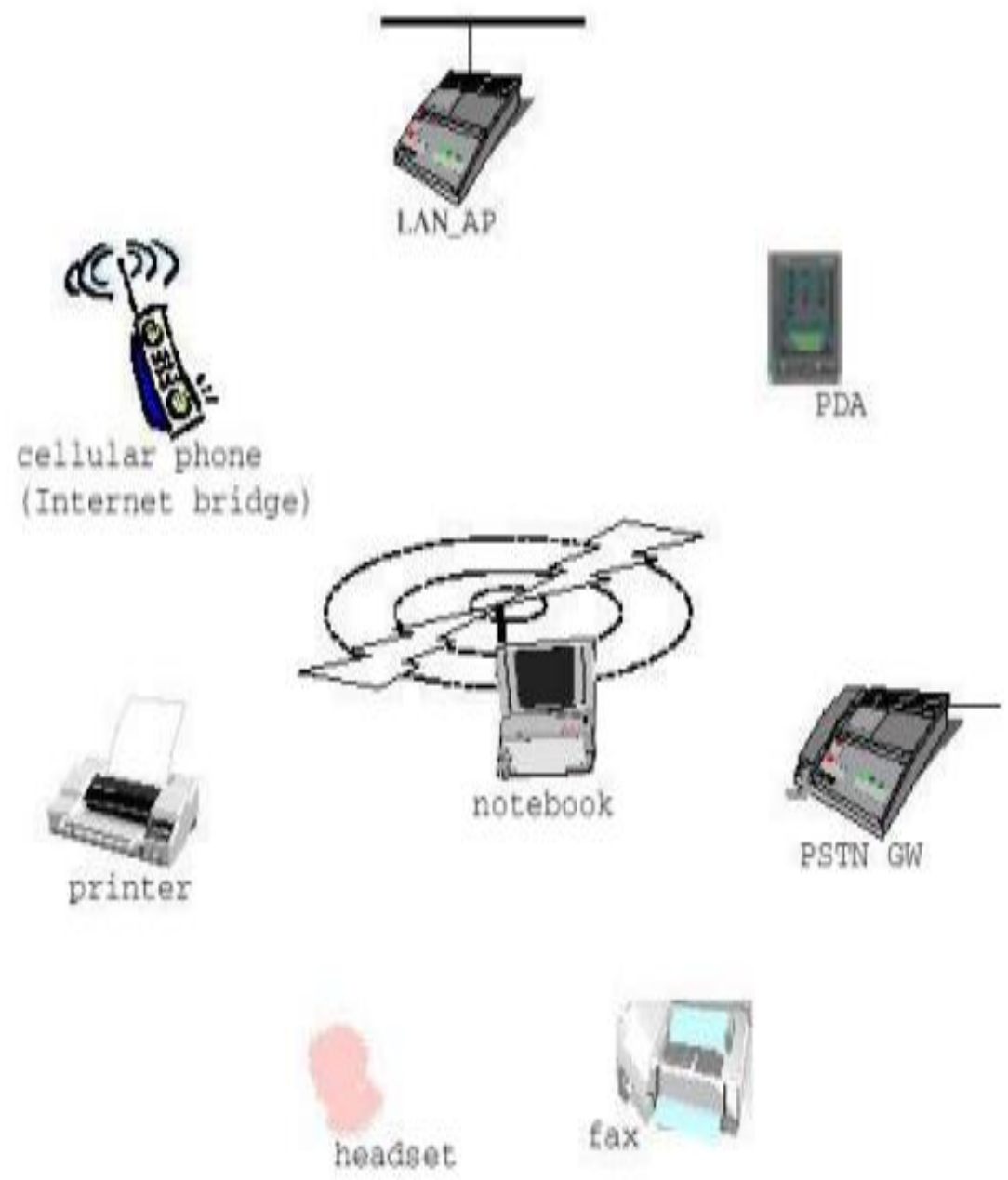

Fig.3. Gi-Fi access devices [12]

Second: security. It notes that security is very useful against penetration in any network with Short Term. Third: Cost low this attribute her high importance, the spread of technology among users flashy techniques) [1]. Fourth::a Short Term. It transmits video and audio files and all the files in the extent of no more than 10 meters are rivals for Bluetooth by high speeds of $5 \mathrm{Gbps}$, while Bluetooth speed of 800 kilobits per second. Fifth: energy consumption. We find that the GI-Fi consumption (2 Miqa watts) compared to very little comparison between WiFi (Miqa 10 watts) and Bluetooth (5 Miqa watt)) [1]. Sixth: The optimal frequency. Australian rival researchers to obtain frequency unoccupied frequency represent not only consume 2 watts Miqa [6]. Seventh: Cost of researchers has competed in the race with the acceleration of life and they are working in the industry and for SIM directions transmitter and receiver at the same time 
as the slice GI-FI Does not cost more than \$ 10) [1]. Eighth: not slowing speeds or overlapping signals. Professor Stan confirms that the frequency space for Gi-Fi into the overlap of signals or frequencies because it is uninhabited, unlike Wi-Fi, for example, does not happen, we find a slowdown in the transfer of any file to any video overlapping signals in the same range of the Frequency Spectrum) [8]. Ninth: the use of semiconductor technology. After a period of development announced the world's Australian Stan and his team with semiconductor leaders that this technique has been developed By use technique Milli-meter waves and 130 nanometer technique snapped a methodology for building electromechanical systems (IBM) of the new chip. Tenth: a station to send its own reception. It is the most important feature characterizes the GI$\mathrm{Fi}$, it turns any device linked him to the station for sending and receiving it allows for multiple devices to communicate with them at one time without hoc basis for plants with high cost they have the same Assembly of the Global Communication Engineers and standards of the International Telecommunications Union standard. [5]. Eleventh: small size. They do not exceed 5 millimeters in length and width, it can be fitted in any electronic device. Twelve o'clock: it has a very short antenna Does not exceed the length of the antenna $1 \mathrm{~mm}$ it boom in the world of wireless communications that I am in the same over 10 meters) [1].

TABLE 1:Compared GI-Fi wireless networks and other

\begin{tabular}{|c|c|c|c|c|}
\hline Features & Gi-Fi & $\mathrm{Li}-\mathrm{Fi}$ & Wi-Fi & Bluetooth \\
\hline speed & 5 GHPS & $1-3.5$ gbp s & 11MPBS & $800 \mathrm{kpbs}$ \\
\hline Range & $10 \mathrm{M}$ & $10 \mathrm{~m}$ & 20-100 meter & | 10 مثر \\
\hline frequency & $57-64 \mathrm{GHZ}$ & $\begin{array}{l}100 \text { time of } \\
\text { TERA HERTZ }\end{array}$ & $2.4 \mathrm{GHz}$ & $2.4 \mathrm{GHz}$ \\
\hline $\begin{array}{l}\text { Energy } \\
\text { consumption }\end{array}$ & $2 \mathrm{MW}$ & & $10 \mathrm{MW}$ & $5 \mathrm{MW}$ \\
\hline $\begin{array}{ll}\text { Net } & \text { work } \\
\text { topology } & \end{array}$ & $\begin{array}{l}\text { Point to } \\
\text { multi point }\end{array}$ & Point to point & Point to multi point & $\begin{array}{l}\text { Bluetooth device } \\
\text { to Bluetooth } \\
\text { device }\end{array}$ \\
\hline $\begin{array}{l}\text { Data transfer } \\
\text { medium }\end{array}$ & $\begin{array}{l}\text { Radio } \\
\text { spectrum }\end{array}$ & $\begin{array}{l}\text { The carrier is } \\
\text { light }\end{array}$ & Radio spectrum & Radio spectrum \\
\hline cost & low & low & high & low \\
\hline AUTHORITY & $\begin{array}{l}\text { NICTA } \\
802.15 .3 \mathrm{c}\end{array}$ & $\begin{array}{l}\text { 802.15.7 IEEE } \\
\text { STANDERD }\end{array}$ & $\begin{array}{l}\text { 802.11B IEEE } \\
\text { STANDERD,WECA }\end{array}$ & $\begin{array}{l}\text { BLUETOOTH } \\
\text { SIG }\end{array}$ \\
\hline SECURETY & Very High & high & low & low \\
\hline $\begin{array}{l}\text { Transportation } \\
\text { devices }\end{array}$ & $\begin{array}{l}\text { ACCESS } \\
\text { POINT }\end{array}$ & LED & ACCES POINT & $\begin{array}{l}\text { ANY } \\
\text { BLUETOOTH } \\
\text { DEVICES }\end{array}$ \\
\hline
\end{tabular}

As the integrated transceiver is extremely small, it can be embedded into devices. The breakthrough will mean the networking of office and home equipment without wires will finally become a reality. The Gi-Fi integrated transceiver chip may be launched by the starting of next year by NICTA. Due to the less cost of chip so many companies are coming forward to launch the chip. The potential of mm wave range for ultra-fast data exchange has prompted many companies like intel, LG, Panasonic, Samsung, Sony\& 
Toshiba to form wireless HD. Specifically wireless HD has a stated goal of enabling wireless connectivity for streaming high definition content between source devices and high definition devices.

\section{Conclusion}

In this paper it has been discussed a number of scientific papers recently about GIFi to its importance because it is the opinion of the boom coming to him with a speed of $5 \mathrm{~GB}$ per second features and energy of consumables 2 megawatts and the length of the antenna does not exceed $1 \mathrm{~mm}$ and the cost does not exceed $\$ 10$ per slice of outsize $5 \mathrm{~mm}$ square-shaped, with a radio transmitter and receiver in the same time address the devices with each other at the same time, also used the semiconductor technology with waves $1 \mathrm{~mm}$ and $130 \mathrm{~nm}$ to reach to deliver innovative of this technique as reported GIfi in the prevention of interference and slow speeds to use Bandwidth unique domain 60 GB Hertz. It is evident that the Gi-Fi technology is expected to be to be the dominant technology for wireless networking. By that point it'll be to supply services with inexpensive, high broadband access, and with terribly high speed giant files swapped inside seconds which can develop wireless home and workplace of future. If the success of $\mathrm{Wi}-\mathrm{Fi}$ and also the at hand wide usage of WiMAX is any indication, Gi-Fi probably will bring wireless broadband to the enterprise in a wholly new means.

\section{References}

[1] M.hika, A.K.SathiyaBama.(2016) "Effective Gi-Fi wireless technology" kartinternational journal of research in computer applications and roboticsissn 2320-7345

[2] Mrs. GIatri .S,Dr.Arutchelvan G.(2016) "An Extensive Comparison Of Existing And Emerging Wireless Technology (Wi-Fi, Wimax, Gi-Fi And Li-Fi) " International Research Journal of Engineering and Technology (IRJET)e-ISSN: 2395 -0056Volume: 03Issue

[3] Jyoti Tewari, Swati Arya (2013)." Evolution of Gi-Fi Technology over other Technologies" IJCSN International Journal of Computer Science and Network, Volume 2, Issue 3, June 2013 ISSN (Online) : 2277-5420 www.ijcsn.org"

[4] Rakesh Kumar Jha, Pooja Kharga(2015)."Gi-Fi Technology: A Technology with Standard Features"International Journal of Computer Applications(0975-8887) International Conference onRecent Trends \& Advancements in Engineering Technology

[5] Vaishali Sharma, Praveen Kumar Sharma (2015)."High-Rate Wireless Communication: Gi-Fi "international conference on recent advances in engineering science and manegement phd chamber of commerce and industry, New delhi

[6] Shikhar Bahl, Rishabh Rai(2015)"Gi-Fi: Future of Wireless Technology"ISSN International Journal of Advanced Research in Computer and Communication EngineeringVol. 4

[7] P.Srikanth,J.R.Thresphine.(2014) "Innovative With GI-FI Technolog " International Journal of Advanced Research inComputer Science \&Technology (IJARCST 2014)

[8] Susmit Pau.(2014) " Future Of Telecommunicationtechnologies:Wi-Fi Vs. Wi-Max Vs. Li-Fi Vs. Gi-Fi" Istp Journal of Research in Electrical andElectronics Engineering (ISTPJREEE)1stInternational Conference on Research in Science, Engineering \& Management (IOCRSEM 2014) 


\section{Gyancity Journal of Electronics and Computer Science, \\ Vol.2, No.2, pp.1-8, September 2017 ISSN: 2446-2918 DOI: 10.21058/gjecs.2017.22001}

[9] Desai Vaishali J,Ramani Shrusti (2014)." GI-FI, the Technology of New Era" International Refereed Journal of Engineering and Science (IRJES) ISSN (Online) 2319-183X, (Print) 2319-1821Vol. 3

[10] Savita Sangappanavar,Poornima GR, C K Narayanappa (2015)."Evolution of Gi-Fi Technology for the Upcoming Generation " International Journal of Engineering and Technical Research (IJETR) ISSN: 2321-0869 Volume-3

[11] http://searchnetworking.techtarget.com/definition/load-balancing : Unified threat management devices: Understanding UTM and its vendors

[12] Shinde, M. V. R., \& Khandagale, M. B. GI-FI Technology.

[13] Gulchakar, P. G., \& Gawai, V. K. (2017). Gi-Fi Technology. International Journal on Wireless, Networking and Mobile Communication Innovations, 3(1).

[14] Hasan, M. K., Saeed, R. A., Hashim, A. H. A., Islam, S., Alsaqour, R. A., \& Alahdal, T. A. (2012). Femtocell network time synchronization protocols and schemes. Research Journal of Applied Sciences, Engineering and Technology, 4(23), 5136-5143.

[15] Hasan, M. K., Ismail, A. F., Abdalla, A. H., Abdullah, K., Ramli, H., Islam, S., \& Saeed, R. A. (2013, August). Inter-cell interference coordination in LTE-A HetNets: A survey on self organizing approaches. In Computing, Electrical and Electronics Engineering (ICCEEE), 2013 International Conference on (pp. 196-201). IEEE. 